\title{
OR-6
}

\section{INVESTIGATION OF TWO-PHASE FLOW HYDRODYNAMICS OF HEAT EXCHANGE TUBE OUTLET FALLING FILM EVAPORATOR}

\author{
V. N. Gushshamova, A. P. Khomyakov, I. S. Kovalev, S. V.Mordanov \\ Ural Federal University of the first President of Russia B. N. Yeltsin, 19 Mira St., \\ Yekaterinburg, 620002, Russia \\ E-mail: 89126634949@yandex.ru
}

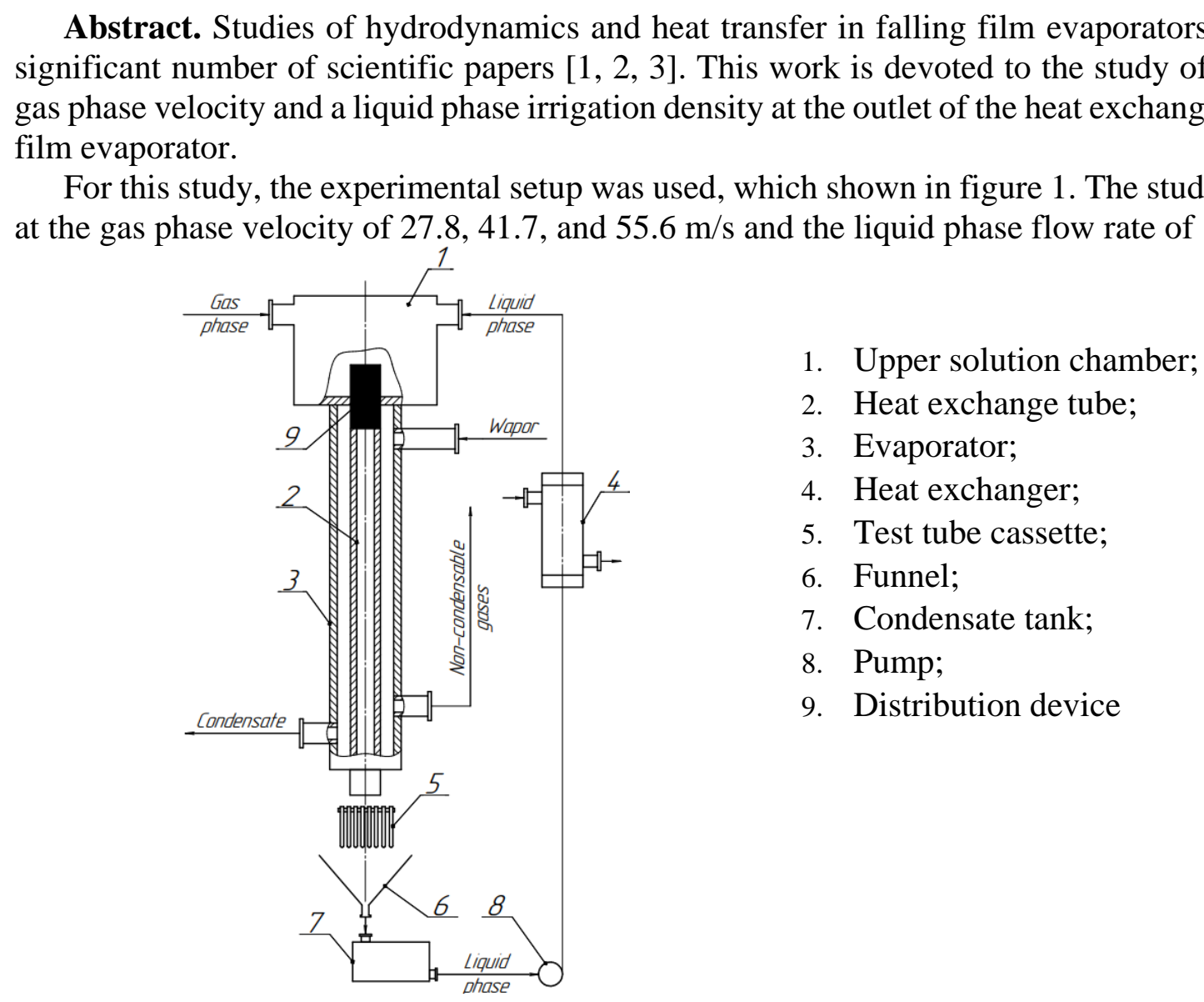

Figure 1. Installation diagram of the film evaporator

The study obtained data on the distribution of the gas phase velocity and the liquid phase irrigation density at a distance of $0.2,0.4,0.6$ and $0.75 \mathrm{~m}$ from the lower section of the heat exchange tube.

The obtained data are necessary for the development of the lower solution chamber and separator of the film-type evaporator.

\footnotetext{
References

1. Joint effects of liquid level and baffle height on the particle distribution and pressure drop in a vertical two-pass circulating fluidized bed evaporator with a baffle / N. Li, Y. Zhang, F. Jiang, G. Qi, H. Wang, R. Su, W. Zhang, N. Shi // Powder Technology. - 2019. Vol. 364. - P. 27-35

2. Comparison of kinetic theory evaporation models for liquid thin-films / E. Aursanda, T. Ytrehus // International Journal of Multiphase Flow. - 2019, Vol. 116. - P. 67-79

3. Modeling and simulation of an industrial falling film evaporator for alumina production/ X. Wang, P. Xiong, K. Suna, Y. Xie, C. Yang // Chemical Engineering Research and Design. - 2019. Vol. 154. - P. 303-315
} 